\title{
Prevalence of malignancy in patients with fever of unknown origin (FUO) demonstrated in 18F-FDG PET-CT - prospective multi-centre study
}

\author{
LI Sonoda*, A Lakhani, S Ghosh-Ray \\ From International Cancer Imaging Society (ICIS) 14th Annual Teaching Course \\ Heidelberg, Germany. 9-11 October 2014
}

\section{Purpose}

18F-FDG PET-CT plays an important role in the management of fever of unknown origin. FUO is defined as "body core temperature $<38.3^{\circ} \mathrm{C}$ on several occasions lasting for $<3$ weeks but no cause found despite routine clinical investigations for $<1$ week in hospital". Malignancy is an important cause of FUO, and the aim of this study is to demonstrate prevalence of malignancy as a cause of FUO demonstrated in PET-CT.

\section{Methods}

A total of 231 patients with FUO were prospectively studied using PET-CT after negative conventional investigations. Final diagnosis was based on biopsy, microbiological tests and imaging follow-up.

\section{Results}

The cause of FUO was identified only in 129/231 (56\%) patients, of which 27 (12\%) were due to malignancy and 102 were due to benign causes.

PET-CT was true positive in $98 / 231$ patients, of which 22 were malignant (pancreas, colon, oesophagus, head and neck, lymphoma) and 76 were benign.

False positive in $18 / 231$ patients, due to increased FDG-uptake in reactive nodes.

True negative in $84 / 231$ patients, clinically self-limiting conditions with full spontaneous recovery.

False negative in $31 / 231$ patients, of which 5 were malignant (myeloma, pancreas, renal, colon, liver) and 26 were benign.
PET-CT identified malignancy in 22/27 (81\%). PET-CT misses poorly-FDG-avid malignancy or lesions embedded within normal physiological uptake.

\section{Conclusion}

In this study $12 \%(27 / 231)$ of FUO are caused by malignancy. PET-CT demonstrated the site of malignancy in $81 \%(22 / 27)$. Although PET-CT plays an important role in the management of FUO, some malignancy may be missed (19\%) so further investigations are still required if spontaneous recovery is not achieved.

Published: 9 October 2014

doi:10.1186/1470-7330-14-S1-P4

Cite this article as: Sonoda et al:: Prevalence of malignancy in patients with fever of unknown origin (FUO) demonstrated in 18F-FDG PET-CT prospective multi-centre study. Cancer Imaging 2014 14(Suppl 1):P4.

Submit your next manuscript to BioMed Central and take full advantage of:

- Convenient online submission

- Thorough peer review

- No space constraints or color figure charges

- Immediate publication on acceptance

- Inclusion in PubMed, CAS, Scopus and Google Scholar

- Research which is freely available for redistribution

Submit your manuscript at www.biomedcentral.com/submit
() Biomed Central

\footnotetext{
* Correspondence: luke@sonoda.co.uk

Paul Strickland Scanner Centre, Mount Vernon Hospital, London, UK
} 